\title{
A women-only clinic for HIV, genitourinary medicine and substance misuse
}

\author{
G A McCarthy, A P Cockell, P D Kell, A S Beevor, F C Boag
}

\begin{abstract}
Objective-To evaluate a multidisciplinary women-only clinic (WOC) providing HIV testing, HIV follow-up, genitourinary screening and a substance misuse service. The clinic is designed to attract women who are at risk of acquiring sexually transmitted infections, including HIV, yet are not using existing medical services. Design-A questionnaire survey and review of the case notes of women attending the WOC during the first seven months (April to October 1991) and comparison with a mixed-sex, daytime genitourinary clinic (John Hunter Clinic), and a HIV out-patients clinic (Kobler Centre) all within St Stephen's Clinic.
\end{abstract}

Results-One hundred and twenty-nine women attended the WOC over the seven month period and 113 completed a questionnaire. The main reasons for attendance included a preference to be seen by a female doctor and staff, the presence of female patients in the waiting area, and the greater convenience of an evening clinic. In the absence of the WOC over half the patients $(56 \%)$ indicated that they would not have attended a genitourinary medicine (GUM) clinic. The WOC attracted significantly more new patients than in the JHC (31.5\% vs $15 \% \mathrm{p}<0.001)$. One hundred and four women $(81 \%)$ were screened for genitourinary infection. Compared with the JHC there were significantly more cases of genital warts $(33.9 \%$ vs $16.1 \%$ p $<0.001)$ and candidosis $(41.5 \%$ vs $22.3 \%$ p $<0.001)$. A greater number of HIV tests were also performed $(19 \%$ vs $9 \%$ p $<0.01)$. Sixteen $(12.4 \%)$ women were HIV positive. Their attendance record at both first appointment $(88 \%$ vs $64 \%$ p $<0.05)$ and subsequent follow-up appointments ( $81 \%$ vs $43 \%$ p < 0.05 ) was significantly higher than a comparable group of women seen by the same doctor (FB) in the Kobler Centre. The women also saw the health adviser more frequently. Although the number of injecting drug users was small (eight), all women currently injecting drugs entered a detoxification programme.

Conclusion-The WOC has become an established and popular service at St Stephen's. Women not previously using medical services are attending. The multidisciplinary nature of the clinic encourages a wider use of medical and paramedical services. Attendance record for HIV positive women has improved significantly. Whether these factors will lead to improved standards of sexual health will require a longer period of audit. Seventy-nine per cent of women indicated they would use a family planning service if available. An integrated family planning clinic was introduced after the audit period.

\section{(Genitourin Med 1992;68:386-389)}

\section{Introduction}

Throughout Britain "women-only" services have become very fashionable. Examples are women-only swimming evenings, health clubs and support groups. The reasons why women request such services have not been explored.

Both HIV positive women attending our $\vec{c}$ clinic and a local self-help group have ? expressed a preference for a women-only multidisciplinary out-patient service; ${ }^{1}$ such a service was particularly requested by women not currently attending any clinic. In response to this we developed a women-only clinic (WOC) to target all women at risk of sexually transmitted infections including HIV. We were particularly interested in attracting women not receiving any medical attention, as we hoped the WOC would act as an introduction to our existing services.

The WOC was designed around a number of core medical services which we believe to be $\dot{\delta}$ essential components of any health care initiative aimed at promoting sexual health and 9 preventing HIV infection. These are screening $D$ for genitourinary infection, family planning and a substance misuse service. The clinic is supported by a range of paramedical services including counselling and psychotherapy, help with social welfare benefits and dietetics.

We have audited the WOC from April October 1991

Development of women-only clinic and services available

The WOC commenced in April 1991. The clinic is held weekly on a Thursday evening between $5.30-7.30 \mathrm{pm}$ by appointment, with open access for urgent problems. With the growth of the clinic the number of appointments has increased from 8 to 16 . An evening session was chosen firstly, because of the difficulty in excluding men from the communal waiting room during the day and, secondly, to encourage attendance by mothers and women reluctant to take time off work. 
The clinic provides genitourinary screening, a substance misuse service, colposcopy and family planning. (Family planning became available in February 1992 and is therefore not included in this audit). The clinic also offers HIV testing with pre-and post-test counselling, and HIV medical follow-up. A health adviser is always available. Once a month the following health care professionals attend to provide specialist advice as required: social worker, psychologist, occupational therapist, dietician and a paediatric liaison nurse (to provide help for women with HIV positive children). Research nurses within genitourinary medicine and HIV medicine are available to recruit women to therapeutic trials as appropriate.

HIV positive women are referred as necessary to the specialist HIV services within the Kobler Centre day ward and Westminster Hospital inpatient wards.

The community drugs team, in conjunction with the clinic doctors, provide a complete programme of care for women using drugs. This includes needle exchange, assessment for prescribing, access to detoxification programmes either as an in-patient or out-patient, hepatitis B vaccination, GUM screening and advice on HIV and safer sex.

\section{Patients}

Access to the clinic is by self-referral or from a general practitioner (GP), hospital doctor, genitourinary clinic (GUM), family planning clinic, or drug dependency unit. Information cards and posters were distributed to all local GPs, family planning clinics, and women's support groups.

\section{Staff}

All the staff are female. The clinic is routinely staffed by a receptionist, initially one and later two doctors, two nurses, and a health adviser. In February 1992 a family planning service commenced, staffed by a family planning trained doctor and nurse (funded by GUM services).

\section{Method}

A self-administered questionnaire was given to all new patients. The questionnaire sought reasons for attendance, source of referral, use of family planning service and whether the women would have attended any other clinic in the absence of the WOC. The case notes were subsequently reviewed to ascertain clinical diagnosis and attendance at follow-up. Data was compared with a mixed-sex day-time GUM clinic (John Hunter Clinic) and a HIV out-patient clinic (Kobler Centre), both within St Stephen's Clinic.

\section{Results}

From April to October 1991, 129 women attended the WOC. A significantly greater number of new patients attended the WOC compared with the John Hunter Clinic ( $p<$ 0.001 ; table 1 ) and a greater proportion were local inhabitants from Riverside $(93.5 \%$ vs
Table 1 Attendance category at WOC and $\mathfrak{F H C ~ ( A p r i l ~ - ~}$ October 1991)

\begin{tabular}{|c|c|c|}
\hline & $\begin{array}{l}W O C \\
n=216\end{array}$ & $\begin{array}{l}f H C \\
n=277\end{array}$ \\
\hline $\begin{array}{l}\text { New patients } \\
\text { Follow-ups` } \\
\text { Rebooks }{ }^{\dagger} \\
\text { HIV tests }\end{array}$ & $\begin{array}{l}68(31 \cdot 5 \%) \\
91(42 \cdot 1 \%) \\
57(26 \cdot 4 \%) \\
40(19 \%)\end{array}$ & $\begin{aligned} 43(15 \%) \mathrm{p}<0.001 \\
155(56 \%) \mathrm{p}<0.01 \\
79(29 \%) \\
26(9 \%) \mathrm{p}<0.01\end{aligned}$ \\
\hline
\end{tabular}

* attending for result or ongoing treatment. attending for result or ongoing treatment.
JHEC or WOC.

$72 \%)$. The clinic was attended by 14 HIV positive women, eight substance misusers, five rape victims, four victims of domestic violence and two girls under 18 years of age. Three women had suffered symptoms for over 2 years but were previously deterred from seeking help as they were reluctant to see a male doctor. Overall, $81 \%$ of women were screened for genitourinary infection and $19 \%$ had HIV tests, twice the rate of women attending the JHC. (see table 1).

Eighty eight per cent (113/129) of women attending the WOC completed a questionnaire (there were no refusals but 16 women were inadvertently not given the questionnaire). Fifty-six per cent of respondents stated that in the absence of the WOC they would not have attended a GUM clinic (table 2). The women attended the WOC because they preferred to see a female doctor $(62 \cdot 2 \%)$, preferred female clinic staff $(50.4 \%)$, and liked to use a waiting room exclusively reserved for women (35\%). All women with young children found child care arrangements easier in the evening (table 3 ). The majority of patients were referred by friends $(29 \%)$, clinic staff $(23 \%)$, general practitioners $(22 \%)$, and family planning clinics (19\%).

During the audit period the WOC attracted $44 \%$ of the HIV positive women registering at St Stephen's for the first time. Sixteen HIV positive women booked into the WOC and 14 attended their first appointment; five women were newly diagnosed, four had just moved to London and five transferred from our existing clinics. The attendance of these $16 \mathrm{HIV}$ positive women was compared with a comparable

Table 2 Choice of alternative clinic in absence of WOC

\begin{tabular}{lc}
\hline Mixed-sex GUM clinic & $32(43 \cdot 8 \%)$ \\
Well woman clinic & $21(28 \cdot 8 \%)$ \\
GP, or FPC & $10(13 \cdot 7 \%)$ \\
Don't know & $7(9 \cdot 6 \%)$ \\
Nowhere & $3(4 \cdot 0 \%)$ \\
Total asked & $73(100 \cdot 0 \%)$ \\
\hline
\end{tabular}

Total asked $73(100 \cdot 0 \%)$

Table 3 Reasons for attending WOC * ${ }^{*}(n=111)$

\begin{tabular}{lll}
\hline Female doctor & $69(62 \cdot 2 \%)$ & \\
Female clinic staff & $56(50 \cdot 4 \%)$ & \\
Evening clinic & $47(47 \cdot 3 \%)$ & \\
Female patients only & $39(35 \cdot 0 \%)$ & (All women with \\
Child care easier & $21(18 \cdot 9 \%)$ & $\begin{array}{l}\text { small children } \\
\text { indicated that child } \\
\text { care was easier). }\end{array}$ \\
\hline
\end{tabular}

${ }^{\star}$ groups are not mutually exclusive. 
group of 14 women booked into the same doctor's (FB) HIV clinic in the Kobler Centre. Ninety-three per cent of women attended regularly for follow-up at the WOC, against only $43 \%$ in the Kobler Centre (see table 4 ). Women attending the WOC also saw the health adviser more frequently.

To date, two women with advanced HIV disease have needed to use the day-care facilities in the Kobler Centre, (or example for blood transfusion). They expressed feeling comfortable being cared for by staff whom they had previously met at the WOC.

Eight substance misusers have attended the WOC. Three were using I.V. drugs; they all entered a methadone detoxification programme and are still complying with treatment. All eight women were screened for genitourinary infection including hepatitis B. Three women were found to be non-immune and they have now commenced a vaccination course. Seven of the women have had HIV tests.

Overall the spectrum of sexually transmitted infections is similar in women attending the WOC and JHC. However, chronic genital infections such as candidosis $(p<0.001)$ and warts $(p<0.001)$ were commoner in women attending the WOC (table 5).

Seventy-nine per cent of women indicated that they would use a family planning service if available. We were initially unable to provide such a service but since February 1992 an integrated family planning service with booked appointments has been in operation. Couples seeking advice together are seen in an area separate from the WOC.

\section{Conclusion}

The WOC represents a new initiative in promoting women's sexual health. The majority of women's health problems are intrinsically related but until recently have been managed in a fragmented way by a variety of specialists including gynaecologists, genitourinary physicians, family planning doctors, general practitioners, and drug dependency units, all operating from geographically separate sites. The increased risk posed by the spread of HIV infection into the heterosexual population, has highlighted the need for a unified approach in the management of sexually transmitted infections.

We have defined four key areas which we believe should be included in the protocol of an inner city clinic attempting to address this problem. (1) screening for genitourinary infection, (2) HIV testing and HIV medical followup, (3) contraception, (4) a substance misuse service. Health education and appropriate counselling are vital in each of these areas. It is important to note that our questionnaire revealed that more than half of the women who attended the WOC would not consequently attend a GUM clinic and would miss out on an important part of sexual health screening. In planning new services it is therefore important to establish the reasons why women fail to attend GUM clinics and adapt services accordingly.

Women attended the WOC with genitourinary infections that were more likely to be chronic or recurrent in nature, such as genital warts or candidosis. This is not unexpected as women with an overt vaginal discharge are unlikely to wait to be seen in the WOC, when they can be seen the same day in the JHC. With chronic problems many women felt they would receive more sympathetic treatment in a women-only clinic.

Providing HIV screening and medical follow-up is an important aspect of the WOC. The number of HIV infected women in the $\mathrm{UK}$ is increasing; $308 \mathrm{HIV}$ infected women were reported in 1990 which increased by $27 \%$ to 390 in 1991. An even sharper rise has been seen at St Stephen's where in 1990, 26 new HIV infected women registered, rising by $88 \%$ to 49 in 1991. Approximately $10 \%$ of all new HIV infections at St Stephen's now occur in women. This percentage is likely to rise further as nationally $20 \%$ of new HIV infections in the UK occurred in women. ${ }^{2}$

Our original survey revealed that a large proportion of HIV positive women were deterred from attending the male dominated out-patient services available in the Kobler Centre. ${ }^{1}$ During the audit period the WOC attracted approximately $44 \%$ of the HIV positive women registering at St Stephen's for the first time. These women attended more reg-

Table 4 HIV positive women: comparison of attendance and use of services in the WOC with the same doctor's clinic in the Kobler Centre ${ }^{\star}$

\begin{tabular}{lll}
\hline & \multicolumn{2}{l}{ No. of women } \\
\cline { 2 - 3 } & $W O C$ & $K C$ \\
\hline $\begin{array}{l}\text { Booked-in for } \\
\text { appointment }\end{array}$ & $16(100 \%)$ & $14(100 \%)$ \\
$\begin{array}{l}\text { Attended first } \\
\text { appointment }\end{array}$ & $14(88 \%)$ & $9(64 \%) \mathrm{p}<0.05$ \\
$\begin{array}{l}\text { Attended regularly for } \\
\text { follow-up }\end{array}$ & $15(93 \%)$ & $6(43 \%) \mathrm{p}<0.05$ \\
$\begin{array}{l}\text { Seen by Health Adviser } \\
\text { each visit }\end{array}$ & $14(88 \%)$ & $4(29 \%)$ \\
$\begin{array}{l}\text { Seen by SW/OT at } \\
\text { clinic visit }\end{array}$ & $5(31 \%)$ & $0(0 \%)$ \\
$\begin{array}{l}\text { Seen by DDU team at } \\
\text { clinic visit }\end{array}$ & $1(6 \%)$ & $0(0 \%)$ \\
Lost to follow up & $1(6 \%)$ & $4(29 \%)$ \\
\hline
\end{tabular}

Table 5 Sexually Transmitted Infections in women attending the WOC and $¥ H C$

\begin{tabular}{|c|c|c|}
\hline & \multicolumn{2}{|c|}{ Number of infections diagnosed } \\
\hline & $\begin{array}{l}\text { WOC } \\
n=65\end{array}$ & $\begin{array}{l}f H C \\
n=1567^{*}\end{array}$ \\
\hline $\begin{array}{l}\text { Candidosis } \\
\text { Genital Warts } \\
\text { Chlamydia } \\
\text { Genital herpes } \\
\text { Bacterial vaginosis } \\
\text { Gonorrhoea } \\
\text { Trichomonas } \\
\text { Scabies/pediculosis } \\
\text { Syphilis }\end{array}$ & $\begin{array}{l}27(41 \cdot 5 \%) \\
22(33 \cdot 9 \%) \\
6(9 \cdot 2 \%) \\
5(7 \cdot 7 \%) \\
4(6 \cdot 2 \%) \\
1(1 \cdot 5 \%) \\
0(0 \%) \\
0(0 \%) \\
0(0 \%)\end{array}$ & $\begin{array}{l}350(22 \cdot 3 \%) \mathrm{p}<0.001 \\
252(16 \cdot 1 \%) \mathrm{p}<0.001 \\
63(4 \cdot 0 \%) \\
73(4 \cdot 7 \%) \\
144(9 \cdot 2 \%) \\
21(1 \cdot 3 \%) \\
23(1.5 \%) \\
8(0.5 \%) \\
3(0 \cdot 2 \%)\end{array}$ \\
\hline
\end{tabular}


ularly for follow-up and made greater use of paramedical services compared to a comparable group of women attending the Kobler Centre.

Coordinated services are still a rarity. Some GUM clinics offer a family planning service and the Brook Advisory Centre in Birmingham has an onsite GUM screening facility, but this is not free. ${ }^{3}$ Queen et al recently pointed out the need for joint GUM and family planning services especially in teenage girls. ${ }^{4}$ This is particularly relevant to Riverside which has one of the highest abortion rates in the UK: 32.5 per 1000 women in 1990 compared with the national rate of $12 \cdot 8$ per 1000 . Interestingly the abortion rate is highest for the $20-34$ year age group; 56.8 compared with 20.0 nationally. A Public Health Directorate study in 1989 , looked at the abortion service in Riverside. This demonstrated that between $30-50 \%$ of women were not using contraception regularly. A recent review of GUM clinic attenders revealed a similar proportion of women $(21 \%-41 \%)$ at risk of unwanted pregnancy. ${ }^{5}$ We hope that the family planning service now available within the WOC will help to reduce the abortion rate. However, for many GUM clinics the source of funding remains an essential problem in the provision of an integrated family planning service. We were unsuccessful in bringing an existing family planning team into the WOC, but as we considered a family planning service to be fundamental in the reduction of unwanted pregnancies we agreed to finance the service with GUM monies.

The number of substance misusers attend- ing the WOC (eight) is still small but this is an area that demands a trusting relationship and is traditionally slow to develop. As $43 \%$ of the HIV positive women at St Stephen's are former or current I.V. drug users we expect the number attending to increase. (An increase in numbers has been seen since the audit).

Use of paramedical services apart from the health adviser was low and these health care professionals now attend monthly as needed.

Women attending the WOC have commented on the relaxed atmosphere of the clinic and staff. One lady remarked "when you are to receive bad news you need a cuddle; male doctors are not allowed to cuddle women". Feeling at ease with the clinic environment and staff is probably an important determinant of regular clinic attendance.

The WOC has now become an established service within St Stephen's. We believe that women's sexual health can be improved by coordinating relevant medical services. The WOC represents a novel and popular approach to this problem. A longer period of audit will be required before the benefits can be fully assessed.

1 Kell PD, Barton SE, Boag FC. Incorporating patients views in planning services for women with HIV Infection. Genitourin Med 1992;68:233-4.

2 Communicable Disease Report: Colindale PHLS 1992;2(4):17-20.

3 Queen HF, Ward $\mathrm{H}$, Smith $\mathrm{C}$, et al. Womens health potential for better coordinating of services. Genitourin potential for better

4 Asboe D, Boag FC, Evans B. Womens health; potential for better coordinating of services. (letter) Genitourin Med 1992;68:65.

5 Birmingham Brook Advisory Centre. Annual Report for $1989 / 1990$. 